\title{
Time spent outdoors and sleep normality: A preliminary investigation
}

\author{
Lindsey A. Wood ${ }^{1,2}$, Madeline M. Tomlinson ${ }^{1,2}$, Jack A. Pfeiffer ${ }^{1,2}$, Kandi L. Walker ${ }^{1,2}$, Rachel J. Keith ${ }^{2,3}$, Ted Smith ${ }^{2,3}$, Ray A. \\ Yeager $^{2,4}$, Aruni Bhatnagar ${ }^{2,3}$, Savanna Kerstiens ${ }^{1,2}$, Delana Gilkey ${ }^{1,2}$, Hong Gao ${ }^{2,3}$, Sanjay Srivastava ${ }^{2,3}$, Joy L. Hart ${ }^{1,2}$
}

\author{
AFFILIATION \\ 1 Department of Communication, University of Louisville, Louisville, \\ United States \\ 2 Christina Lee Brown Envirome Institute, University of Louisville, \\ Louisville, United States \\ 3 School of Medicine, University of Louisville, Louisville, United States \\ 4. School of Public Health and Information Sciences, University of \\ Louisville, Louisville, United States
}

CORRESPONDENCE TO

Joy L. Hart. Department of Communication, University of Louisville,
Louisville, KY 40292, United States. E-mail: joy.hart@louisville.edu ORCID ID: https://orcid.org/0000-0003-3220-2638

KEYWORDS

sleep, health risks, nature, time outdoors, greenness

Received: 7 September 2020, Revised: 1 January 2021,

Accepted: 3 January 2021

\begin{abstract}
INTRODUCTION Sleep deficiency is associated with health risks, and time outdoors is related to health benefits. This study assessed time outdoors and its association with sleep normality.

METHODS As part of a health study in Louisville, Kentucky, 735 participants completed questionnaires on their health status, behaviors, neighborhoods, and demographics in 2018-2019. The measures included information on sleep, time outdoors, and mental and physical health. Participant characteristics were assessed by dichotomized sleep normality ( $\mathrm{N}=728)$, and logistic regression $(\mathrm{N}=709)$ examined potential associations between time outdoors and sleep.

RESULTS As time spent outdoors increased from $\leq 4$ hours to $>4-\leq 8$ hours (OR=1.04; 95\% CI: $0.65-1.64)$ and $>8-$ $\leq 12$ hours (OR=1.17; 95\% CI: $0.63-2.17$ ), odds of normal
\end{abstract}

sleep increased; however, those who spent $>12-\leq 16$ hours (OR $=0.63$; 95\% CI: $0.31-1.27$ ) or $>16$ hours (OR $=0.83$; $95 \%$ CI: $0.45-1.53$ ) outdoors had a lower likelihood of normal sleep. No associations between time outdoors and sleep were significant. There was a significant trend of less bodily pain associated with normal sleep $(\mathrm{p}<0.001)$ and in the association of depression and sleep, where odds of normal sleep decreased as depression severity increased ( $p<0.001)$. ConCLUSIONS Consistent with extant literature, findings indicate associations between less pain and increased odds of normal sleep and between higher severity of depression and lower odds of normal sleep. Findings for an overall association between time outdoors and sleep normality were not significant. Future work should seek to better explicate the predictor variables to assess how greenness and activity type shape associations with sleep.

\section{INTRODUCTION}

Lack of sleep is associated with poor health outcomes, such as diabetes, obesity, and cardiovascular disease (CVD) ${ }^{1-}$ 5. Despite the importance of sleep, many people in the US report that sleepiness interferes with daily activities ${ }^{6}$ and fewer than half report awaking feeling rested ${ }^{7}$. To offset the damaging effects of sleep deficit, researchers have examined improving sleep quality. Contributors to better sleep include a daily routine, physical activity, and exposure to green spaces ${ }^{8,9}$. Living in a greener neighborhood has been suggested to lower the risk of short sleep duration ${ }^{10}$ and exposure to nature provides protection from insufficient sleep ${ }^{11}$. However, less is known regarding overall time outdoors and sleep quality.

Spending time outside is associated with positive health outcomes, including decreased risk of diabetes, obesity, and depression ${ }^{12,13}$. Some investigations indicate a relationship between time outside and sleep quality. Murray et al. ${ }^{8}$ reported that the interaction between increased time outdoors and increased physical activity had a positive association with total sleep time ${ }^{8}$. In addition, time outside in the morning can improve college students' sleep quality ${ }^{14}$ and less exposure to daylight influences sleep deficiencies for the elderly ${ }^{15}$.

The purpose of this study was to assess the association 
between total time spent outdoors per week and sleep normality. We hypothesize that an increase in time outdoors will increase the odds of normal sleep patterns.

\section{METHODS}

\section{Sample}

During the summers of 2018 and 2019, data were collected from 735 participants (aged 25-70 years) in Green Heart Louisville's health study (i.e., Health, Environment, and Action in Louisville-HEAL). HEAL is a non-randomized clinical trial to assess how an intervention of added greenery may affect health, especially risks for and incidence of CVD. Participants completed questionnaires on health status, health behavior, neighborhood characteristics, and demographic information (Supplementary file Figure 1 gives the study design). Due to missing data, the analytic sample for crude analysis and for the regression was 728 and 709, respectively. This study was approved by the University of Louisville's Institutional Review Board.

\section{Measures}

Sleep

Participants reported sleep habits using Patient Health Questionnaire-9 (PHQ-9) ${ }^{16}$ item 3: 'Over the past 2 weeks, how often have you been bothered by any of the following problems - trouble falling asleep, staying asleep or sleeping too much?', with responses 'not at all', 'several days', 'more than half the days' or 'nearly every day'. This item does not differentiate between insomnia and hypersomnia, but rather includes both as sleeping problems. Therefore, responses were dichotomized as 'normal sleep' and 'non-normal sleep', where normal included 'not at all' responses, and non-normal included all other responses.

\section{Time spent outdoors}

Time outdoors per week was reported from participant answers to the question: 'How much time per week do you spend outdoors in nature?'. Response options were 13 categories that ranged from 'less than 1 hour' to 'more than 16 hours'. Due to small sample sizes in some response areas, the categories were collapsed to five, so that time outdoors responses were analyzed as: $\leq 4,>4-\leq 8,>8-\leq 12,>12-\leq 16$, and $>16$ hours.

\section{Demographic and other variables}

Participants were categorized by several demographic characteristics: age, gender, and race. These characteristics, as well as other variables related to perceptions and behavior, were considered as potential confounders (Table 1). Participants reported self-assessments of overall health, level of bodily pain, feeling safe walking in their neighborhood, regular exercise (over 10 minutes duration), smoking status, typical work area, depression status (PHQ9) ${ }^{16}$, and stress level (Perceived Stress Scale, PSS) ${ }^{17}$. Lastly, the Perceived Benefits of Nature (PBN) ${ }^{18}$ questionnaire assessed participant views of nature with higher scores indicating greater perceived benefits.

\section{Statistical analysis}

Crude associations were assessed between all variables and

Table 1. Participant characteristics stratified by sleep status, Louisville, Kentucky, 2018-2019 (N=728)

\begin{tabular}{|c|c|c|c|c|}
\hline Characteristics & $\begin{array}{c}\text { Normal sleep } \\
(\mathrm{n}=296) \\
\mathrm{n}(\%) \text { or median (IQR) }\end{array}$ & $\begin{array}{c}\text { Non-normal sleep } \\
(n=432) \\
n(\%) \text { or median (IQR) }\end{array}$ & $\mathbf{p}^{*}$ & Missing \\
\hline Age (years) & $51.0(37.4-61.1)$ & $50.9(38.2-60.3)$ & 0.788 & 0 \\
\hline Gender & & & 0.008 & 0 \\
\hline Female & $163(55.1)$ & $280(64.8)$ & & \\
\hline Male & $133(44.9)$ & $152(35.2)$ & & \\
\hline Race & & & 0.836 & 7 \\
\hline White & $230(78.8)$ & $333(77.6)$ & & \\
\hline Black & $51(17.5)$ & 76 (17.7) & & \\
\hline Other & $11(3.8)$ & $20(4.7)$ & & \\
\hline Income (US\$) & & & 0.292 & 40 \\
\hline$<20000$ & $61(22.2)$ & $109(26.4)$ & & \\
\hline 20000-44999 & $75(27.3)$ & $130(31.5)$ & & \\
\hline 45000-64999 & $71(25.8)$ & 85 (20.6) & & \\
\hline 65000-89999 & $36(13.1)$ & $51(12.4)$ & & \\
\hline $90000-124999$ & $23(8.4)$ & $31(7.5)$ & & \\
\hline$\geq 125000$ & $9(3.3)$ & $7(1.7)$ & & \\
\hline
\end{tabular}


Table 1. Continued

\begin{tabular}{|c|c|c|c|c|}
\hline Characteristics & $\begin{array}{c}\text { Normal sleep } \\
(n=296) \\
n(\%) \text { or median (IQR) }\end{array}$ & $\begin{array}{c}\text { Non-normal sleep } \\
\text { (n=432) } \\
\text { n (\%) or median (IQR) }\end{array}$ & $\mathbf{p}^{*}$ & Missing \\
\hline Hours spent outdoors per week & & & 0.361 & 3 \\
\hline$\leq 4$ & $118(40.1)$ & $190(44.1)$ & & \\
\hline$>4-\leq 8$ & 77 (26.2) & $110(25.5)$ & & \\
\hline$>8-\leq 12$ & $42(14.3)$ & $41(9.5)$ & & \\
\hline$>12-\leq 16$ & $22(7.5)$ & $34(7.9)$ & & \\
\hline$>16$ & $35(11.9)$ & $56(13.0)$ & & \\
\hline Health & & & $<0.0001$ & 1 \\
\hline Excellent & $22(7.4)$ & $14(3.25)$ & & \\
\hline Very good & $128(43.2)$ & $96(22.3)$ & & \\
\hline Good & $117(39.5)$ & $203(47.1)$ & & \\
\hline Fair & $23(7.8)$ & $98(22.74)$ & & \\
\hline Poor & $6(2.0)$ & $20(4.7)$ & & \\
\hline Bodily pain in past 4 weeks & & & $<0.0001$ & 2 \\
\hline None & $95(32.3)$ & $35(8.2)$ & & \\
\hline Very mild & $88(29.9)$ & $106(24.7)$ & & \\
\hline Mild & $54(18.4)$ & $91(21.2)$ & & \\
\hline Moderate & $38(12.9)$ & $111(25.9)$ & & \\
\hline Severe/very severe & $19(6.5)$ & $86(20.1)$ & & \\
\hline $\begin{array}{l}\text { Feel safe to walk neighborhood, day } \\
\text { or night }\end{array}$ & & & 0.001 & 6 \\
\hline Strongly agree & $45(15.5)$ & $36(8.4)$ & & \\
\hline Agree & $115(39.5)$ & $144(33.4)$ & & \\
\hline Neither agree nor disagree & $36(12.4)$ & $71(16.5)$ & & \\
\hline Disagree & $65(22.3)$ & $103(23.9)$ & & \\
\hline Strongly disagree & $30(10.3)$ & 77 (17.9) & & \\
\hline Regular exercise & & & 0.008 & 8 \\
\hline Yes & $194(66.0)$ & $239(56.1)$ & & \\
\hline No & $100(34.0)$ & $187(43.9)$ & & \\
\hline Smoker & & & 0.005 & 39 \\
\hline Never & 155 (55.9) & $180(44.3)$ & & \\
\hline Former & $56(18.9)$ & $78(19.2)$ & & \\
\hline Current & $71(25.2)$ & $149(36.5)$ & & \\
\hline Work area & & & 0.0021 & 81 \\
\hline Mainly outdoors & $32(11.9)$ & $45(11.9)$ & & \\
\hline Travel to different buildings/sites & $15(5.6)$ & $17(4.5)$ & & \\
\hline In a motor vehicle & $4(1.5)$ & $8(2.1)$ & & \\
\hline Mainly indoors & $180(66.9)$ & $206(54.5)$ & & \\
\hline Unemployed & $38(14.1)$ & $102(27.0)$ & & \\
\hline Depression & & & $<0.0001$ & 0 \\
\hline None or minimal & $259(87.5)$ & $153(35.4)$ & & \\
\hline Mild & $31(10.5)$ & $144(33.3)$ & & \\
\hline Moderate & $1(0.3)$ & 74 (17.1) & & \\
\hline Moderately severe & $4(1.4)$ & $38(8.8)$ & & \\
\hline Severe & $1(0.3)$ & $23(5.3)$ & & \\
\hline
\end{tabular}


Table 1. Continued

\begin{tabular}{|c|c|c|c|c|}
\hline Characteristics & $\begin{array}{c}\text { Normal sleep } \\
(n=296) \\
\text { n (\%) or median (IQR) }\end{array}$ & $\begin{array}{c}\text { Non-normal sleep } \\
\text { (n=432) } \\
\text { n (\%) or median (IQR) }\end{array}$ & $\mathbf{p}^{*}$ & Missing \\
\hline Stress & & & $<0.0001$ & 0 \\
\hline Low & $189(63.8)$ & $143(33.1)$ & & \\
\hline Moderate & $98(33.1)$ & $240(55.6)$ & & \\
\hline High & $9(3.0)$ & $49(11.3)$ & & \\
\hline Perceived benefits of nature & $57.0(49.0-66.0)$ & $57.0(47.0-65.0)$ & 0.972 & 0 \\
\hline
\end{tabular}

PHQ: Patient Health Questionnaire. *Based on chi-squared, Fischer's exact, or Mann-Whitney U tests.

the dichotomized sleep variable for 728 participants. When comparing categorical variables with sleep, chi-squared or Fisher's exact test were conducted depending on the distribution of the variable. When assessing continuous variables with sleep, Mann-Whitney U tests were conducted due to the non-normal distribution of continuous variables.

To determine the association of time spent outdoors per week and sleep, logistic regression was utilized $(n=709)$. Although not all variables were found to be statistically significant in crude analysis, an initial model included each variable. However, variables were retained in the model only if they were identified as confounders using backward elimination. Variables not retained were: age, gender, race, income, smoker status, and work area. Reported results include adjusted odds ratios for normal sleep, with $95 \%$ confidence intervals, of categorized time spent outdoors per week, with the reference being $\leq 4$ hours. Associations were considered significant for $\mathrm{p} \leq 0.05$. Analyses were conducted using SAS (version 9.4).

\section{RESULTS}

Participant characteristics stratified by sleep status are shown in Table 1 (see Supplementary file Table 1 for more detailed characteristics). The median age of normal sleepers was 51 years. In crude analysis, normal sleep was more prevalent in females (55.1\%) and Whites (78.8\%) than in males and Non-Whites. Further, normal sleep was more prevalent in those who spent less time outside per week; perceived better general health, less pain, and a higher sense of safety when walking in their neighborhood; engaged in regular exercise, no smoking, and mainly indoor work; and experienced less severe depression and less stress.

The results of the final logistic regression model produced after backward elimination are shown in Table 2. General health was retained in the model but later removed due to multicollinearity. The main predictor of this analysis was time spent outdoors per week. In the adjusted model, as time spent outdoors increased from $\leq 4$ hours to $>4-\leq 8$ hours (OR=1.04; 95\% CI: 0.65-1.64) and >8 - $\leq 12$ hours $(\mathrm{OR}=1.17 ; 95 \% \mathrm{CI}: 0.63-2.17)$, the odds of normal sleep increased; however, those who spent $>12-\leq 16$ hours
Table 2. Adjusted odds ratios for normal sleep, Louisville, Kentucky, 2018-2019 (N=709)

\begin{tabular}{|c|c|c|c|}
\hline Characteristics & AOR & $95 \% \mathrm{CI}$ & p-trend \\
\hline Hours outside per week & & & 0.374 \\
\hline$\leq 4$ & Ref. & & \\
\hline$>4-\leq 8$ & 1.04 & $0.65-1.64$ & \\
\hline$>8-\leq 12$ & 1.17 & $0.63-2.17$ & \\
\hline$>12-\leq 16$ & 0.63 & $0.31-1.27$ & \\
\hline$>16$ & 0.83 & $0.45-1.53$ & \\
\hline Bodily pain & & & $<0.001$ \\
\hline None & Ref. & & \\
\hline Very mild & 0.26 & $0.15-0.46$ & \\
\hline Mild & 0.27 & $0.15-0.50$ & \\
\hline Moderate & 0.27 & $0.14-0.50$ & \\
\hline Severe/very severe & 0.30 & $0.13-0.67$ & \\
\hline Feel safe to walk neighborhood & & & 0.342 \\
\hline Strongly disagree & Ref. & & \\
\hline Disagree & 1.84 & $0.95-3.56$ & \\
\hline Neither agree nor disagree & 1.11 & $0.54-2.30$ & \\
\hline Agree & 1.43 & $0.77-2.66$ & \\
\hline Strongly agree & 2.00 & $0.94-4.26$ & \\
\hline \multicolumn{4}{|l|}{ Exercise regularly } \\
\hline No & Ref. & & \\
\hline Yes & 0.87 & $0.58-1.31$ & \\
\hline Depression & & & $<0.001$ \\
\hline None or minimal & Ref. & & \\
\hline Mild & 0.13 & $0.08-0.22$ & \\
\hline Moderate & 0.01 & $0.01-0.52$ & \\
\hline Moderately severe & 0.04 & $0.01-0.17$ & \\
\hline Severe & 0.02 & $0.01-0.14$ & \\
\hline Stress & & & 0.879 \\
\hline Low & Ref. & & \\
\hline Moderate & 0.81 & $0.53-1.22$ & \\
\hline High & 2.90 & $0.89-9.52$ & \\
\hline Perceived benefits of nature & 1.01 & $0.99-1.02$ & \\
\hline
\end{tabular}

AOR: adjusted odds ratio. AOR and $95 \%$ CI were estimated from logistic regression for normal sleep. General health was removed from the model due to multicollinearity. Ref.: reference. 
(OR=0.63; 95\% CI: $0.31-1.27)$ or $>16$ hours $(\mathrm{OR}=0.83 ; 95 \%$ CI: $0.45-1.53$ ) outdoors had a lower likelihood of normal sleep. No estimates of association between time outdoors and sleep were significant. Likewise, there was no significant trend ( $\mathrm{p}$-trend=0.374).

Compared to those who experienced no bodily pain in the past four weeks, those with any pain had lower likelihood of normal sleep. In fact, those that experience very mild $(\mathrm{OR}=0.26$; 95\% CI: 0.15-0.46), mild (OR=0.27; 95\% CI: $0.15-0.50)$, moderate $(\mathrm{OR}=0.27 ; 95 \% \mathrm{CI}: 0.14-0.50)$ or severe/very severe $(\mathrm{OR}=0.30 ; 95 \% \mathrm{CI}: 0.13-0.67)$ pain had significantly reduced odds of normal sleep. There was a significant trend of less pain being associated with normal sleep (p-trend<0.001).

Additionally, compared to those with no or minimal depression, those with mild (OR=0.13; 95\% CI: 0.08-0.22), moderate (OR=0.01; 95\% CI: 0.01-0.52), moderately severe $(\mathrm{OR}=0.04$; 95\% CI: $0.01-0.17)$ or severe $(\mathrm{OR}=0.02$; $95 \% \mathrm{CI}$ : 0.01-0.14) depression had significantly lower likelihood of normal sleep. There was a significant trend in the association of depression and sleep, where the odds of normal sleep decreased as depression severity increased (p-trend<0.001).

\section{DISCUSSION}

Sufficient sleep has been shown to reduce the risk of adverse health outcomes, including CVD, diabetes, and obesity $^{10}$. Therefore, exploring predictors of sleep quality is pertinent for improving individual and community health. Consistent with previous research, we found individuals who spent $\leq 12$ hours outside per week had higher odds of normal sleep compared to those who spent little to no time outside. However, our findings differ from previous work indicating time spent in green spaces improves sleep. That is, we did not find a significant relationship between time outdoors and sleep normality, whereas other studies have found associations between greenness and sleep ${ }^{10,11}$. Thus, future work needs to consider specific characteristics of time outside (e.g. time outdoors may not involve green spaces or allow for an appreciation of them) and to more clearly specify what time outdoors in nature means, as there is no clear evidence to suggest that time spent in non-green outdoor spaces has the same health benefits as time spent in green outdoor spaces. In addition, this study highlighted associations between less bodily pain and greater odds of normal sleep, and between higher levels of depression and lower likelihood of normal sleep, findings consistent with extant literature ${ }^{19}$.

\section{Limitations}

The study has several limitations. First, the cross-sectional design allows for assessment of association but prohibits assessment of temporality. Thus, future work is needed to examine any possibility of causal relationships. Second, selfreported information may be subject to recall bias. Third, few participants reported high stress, leading to imprecise CIs for this association. Despite the limitations, the study provides insights for future work exploring time outdoors and sleep quality.

\section{CONCLUSIONS}

Our findings reinforce previous work on the relationship between experiencing depression or pain and sleep normality. The association of time outdoors with sleep indicates a possible threshold effect, in that spending $\leq 12$ hours outdoors per week increased the odds of reporting sleep normality; however, findings for an overall association were non-significant. Future research should seek to explicate possible relationships between sleep and time in any outdoor setting, in greenness, and in specific outdoor activities.

\section{REFERENCES}

1. Buxton OM, Marcelli E. Short and long sleep are positively associated with obesity, diabetes, hypertension, and cardiovascular disease among adults in the United States. Soc Sci Med. 2010;71(5):1027-1036. doi:10.1016/j.socscimed.2010.05.041

2. Shan Z, Ma H, Xie M, et al. Sleep duration and risk of type 2 diabetes: a meta-analysis of prospective studies. Diabetes Care. 2015;38(3):529-537. doi:10.2337/dc14-2073

3. Cappuccio FP, Taggart FM, Kandala NB, et al. Meta-analysis of short sleep duration and obesity in children and adults. Sleep. 2008;31(5):619-626. doi:10.1093/sleep/31.5.619

4. Yazdanpanah MH, Homayounfar R, Khademi A, Zarei F, Shahidi A, Farjam M. Short sleep is associated with higher prevalence and increased predicted risk of cardiovascular diseases in an Iranian population: Fasa PERSIAN Cohort Study. Sci Rep. 2020;10:4608. doi:10.1038/s41598-020-61506-0

5. Hoevenaar-Blom MP, Spijkerman AM, Kromhout D, van den Berg JF, Verschuren WM. Sleep duration and sleep quality in relation to 12-year cardiovascular disease incidence: the MORGEN study. Sleep. 2011;34(11):1487-1492. doi:10.5665/sleep.1382

6. National Sleep Foundation. Sleep in America ${ }^{\circledR}$ Poll 2020: Americans Feel Sleepy 3 Days a Week, With Impacts on Activities, Mood \& Acuity. https://www.sleepfoundation. org/wp-content/uploads/2020/03/SIA-2020-Q1-Report. pdf?x72630\#: :text=The $\% 20$ National $\% 20$ Sleep $\% 20$ Foundation's\%202020,mental $\% 20$ a cuity $\% 2 \mathrm{C} \% 20$ productivity $\% 20$ and $\% 20$ more.\&text $=$ In $\% 20$ the $\% 20$ most $\% 20$ commonly $\% 20$ reported, sleepy $\% 20$ can $\% 20$ impact\%20their\%20mood. Accessed September 7, 2020.

7. National Sleep Foundation. Sleep in America ${ }^{\circledR}$ Poll 2019: Sleep Health \& Scheduling. https://www.sleepfoundation. org/wp-content/uploads/2019/02/SIA_2019_Sleep_Health_ and_Scheduling.pdf?x90559. Accessed September 7, 2020.

8. Murray K, Godbole S, Natarajan L, et al. The relations between sleep, time of physical activity, and time outdoors among adult women. PLoS One. 2017;12(9):e0182013. doi:10.1371/journal.pone.0182013

9. Moss TG, Carney CE, Haynes P, Harris AL. Is daily routine 
important for sleep? An investigation of social rhythms in a clinical insomnia population. Chronobiol Int. 2015;32(1):92102. doi:10.3109/07420528.2014.956361

10. Astell-Burt T, Feng X, Kolt GS. Does access to neighbourhood green space promote a healthy duration of sleep? Novel findings from a cross-sectional study of 259319 Australians. BMJ Open. 2013;3(8):e003094. doi:10.1136/bmjopen-2013-003094

11. Grigsby-Toussaint DS, Turi KN, Krupa M, Williams NJ, PandiPerumal SR, Jean-Louis G. Sleep insufficiency and the natural environment: Results from the US Behavioral Risk Factor Surveillance System survey. Prev Med. 2015;78:78-84. doi:10.1016/j.ypmed.2015.07.011

12. Richardson $\mathrm{MB}$, Chmielewski $\mathrm{C}, \mathrm{Wu} \mathrm{CYH}$, et al. The effect of time spent outdoors during summer on daily blood glucose and steps in women with type 2 diabetes. J Behav Med. 2020;43(5):783-790. doi:10.1007/s10865-019-00113-5

13. Beyer KMM, Szabo A, Hoormann K, Stolley M. Time spent outdoors, activity levels, and chronic disease among American adults. J Behav Med. 2018;41(4):494-503. doi:10.1007/s10865-018-9911-1

14. Carney CE, Edinger JD, Meyer B, Lindman L, Istre T. Daily activities and sleep quality in college students. Chronobiol Int. 2006;23(3):623-637. doi:10.1080/07420520600650695

15. Mishima K, Okawa M, Shimizu T, Hishikawa Y. Diminished melatonin secretion in the elderly caused by insufficient environmental illumination. J Clin Endocrinol Metab. 2001;86(1):129-134. doi:10.1210/jcem.86.1.7097

16. Spitzer RL, Kroenke K, Williams JB. Validation and utility of a self-report version of PRIME-MD: the PHQ primary care study. Primary Care Evaluation of Mental Disorders. Patient Health Questionnaire. JAMA. 1999;282(18):1737-1744. doi:10.1001/jama.282.18.1737

17. Cohen S. Perceived Stress Scale. Mind Garden. https://www. mindgarden.com/documents/PerceivedStressScale.pdf. Published 1994. Accessed September 7, 2020.

18. Dzhambov AM. Perceived Benefits of Nature Questionnaire: Preliminary Results. Ecopsychology. 2014;6(2):109-115. doi:10.1089/eco.2013.0108

19. Strine TW, Chapman DP. Associations of frequent sleep insufficiency with health-related quality of life and health behaviors. Sleep Med. 2005;6(1):23-27. doi:10.1016/j.sleep.2004.06.003

\section{CONFLICTS OF INTEREST}

The authors have completed and submitted the ICMJE Form for Disclosure of Potential Conflicts of Interest and none was reported.

\section{FUNDING}

This work was supported, in part, by grants from the National Institute of Environmental Health Sciences of the National Institutes of Health (NIH; Award Number R01 ES 029846 and P42 ES023716); The Nature Conservancy (TNC); and the Christina Lee Brown Envirome Institute at the University of Louisville. The content is solely the responsibility of the authors and does not necessarily represent the official views of the NIH, TNC, or the University of Louisville. The funding sponsors had no role in study design; data collection, analyses, or interpretation; manuscript preparation; or the decision to publish the results.

\section{PROVENANCE AND PEER REVIEW}

Not commissioned; externally peer reviewed. 